\title{
Carcinoma of the Conjunctiva Pathologic TNM Finding v7
}

National Cancer Institute

\section{Source}

National Cancer Institute. Carcinoma of the Conjunctiva Pathologic TNM Finding v7. NCI

Thesaurus. Code C88587.

A pathologic finding about one or more characteristics of carcinoma of the conjunctiva, following the rules of the TNM AJCC V7 classification system. Complete resection of the primary site is indicated (if possible). The specimen should be thoroughly sampled for histologic study of surgical margins, type of tumor, and grade of malignancy. (from AJCC 7th Ed.) 